\title{
The pivotal role of VEGF on glomerular macrophage infiltration in advanced diabetic nephropathy
}

\author{
Waichi Sato ${ }^{1}$, Tomoki Kosugi ${ }^{1}$, Li Zhang ${ }^{1}$, Carlos A Roncal ${ }^{1}$, Marcelo Heinig ${ }^{1}$, Martha Campbell-Thompson ${ }^{2,3}$, \\ Yukio Yuzawa ${ }^{4}$, Mark A Atkinson², Maria B Grant ${ }^{5}$, Byron P Croker ${ }^{3,6}$ and Takahiko Nakagawa'
}

A growing body of evidence implicates inflammation in the development of diabetic nephropathy. We recently reported that diabetic endothelial nitric oxide synthase knockout (eNOS KO) mice develop advanced glomerular lesions resembling human diabetic nephropathy. Vascular endothelial growth factor (VEGF) is a major factor in diabetic nephropathy, and is known to be chemotactic for macrophages. Herein, we examined the association of VEGF with macrophage infiltration in experimental diabetic nephropathy. Glomerular macrophage infiltration was markedly increased in diabetic eNOS KO mice compared to diabetic C57BL/6 mice, and correlated with glomerular injury, such as mesangiolysis, glomerular microaneurysm and nodular lesions of glomerular sclerosis. An elevation of podocyte VEGF expression correlated with infiltration of Flt-1-positive macrophage in injured glomeruli in diabetic eNOS KO mice, suggesting that VEGF could contribute to macrophage migration. Neither renal nNOS nor iNOS expression was altered in both C57BL/6 and eNOS KO mice. To determine if lack of NO could affect VEGF activation of macrophages, we examined if exogenous NO can block macrophage migration induced by VEGF in in vitro studies. Exogenous NO blocked macrophage migration and hypertrophy in response to VEGF. NO mediated these effects in part by downregulating Flt-1 expression on the macrophage. In summary, NO negatively regulates VEGF-induced macrophage migration by inhibiting Flt-1 expression. The VEGF-endothelial NO uncoupling pathway might partially explain how VEGF causes glomerular disease in diabetes. Laboratory Investigation (2008) 88, 949-961; doi:10.1038/labinvest.2008.60; published online 7 July 2008

KEYWORDS: eNOS; NO; Flt-1; diabetes

Infiltration of immune cells has been considered to be important in the development and progression of diabetic nephropathy. ${ }^{1,2}$ The macrophage is one of the central mediators of renal vascular inflammation, and its accumulation is a characteristic feature of diabetic nephropathy. ${ }^{3-5}$ Macrophages have been shown to cause proteinuria and mesangial cell injury in experimental glomerulonephritis. ${ }^{6}$ Macrophage infiltration also has an important role in mesangiolysis in patients with congestive heart failure, ${ }^{7}$ which is a phenomenon observed in human advanced diabetic nephropathy. Although macrophage infiltration is therefore likely to be important in the development of diabetic nephropathy, to our knowledge no detailed molecular mechanisms for macrophage migration have been explored in diabetic nephropathy.
The diabetic condition, which includes high serum levels of glucose or advanced glycation end products, has been shown to induce intercellular adhesion molecule-1 (ICAM-1) and monocyte chemoattractant protein-1 (MCP-1) in the kidney. ${ }^{8,9}$ The important role of ICAM-1 on development of diabetic nephropathy was demonstrated using ICAM-1deficient mice in which diabetes resulted in less glomerular injury with macrophage infiltration in kidney. ${ }^{10}$ Similarly, MCP-1 expression is associated with macrophage infiltration in diabetic kidney. ${ }^{3,11}$ MCP-1 and ICAM-1 may coordinate to stimulate leukocyte chemotaxis and adhesion, respectively. ${ }^{1,2}$ Although MCP-1 and ICAM-1 are likely to be key factors in modulating the inflammatory response in diabetic renal disease, it also remains possible that other chemotactic factors may have contributory roles.

\footnotetext{
'Division of Nephrology, Department of Medicine, University of Florida, Gainesville, FL, USA; ${ }^{2}$ Molecular Pathology and Immunology Core Laboratory, Department of Pathology, University of Florida, Gainesville, FL, USA; ${ }^{3}$ Department of Pathology, Immunology, and Laboratory Medicine, North Florida/South Georgia Veterans Health System, Gainesville, FL, USA; ${ }^{4}$ Department of Nephrology, Nagoya University Graduate School of Medicine, Nagoya, Aichi, Japan; ${ }^{5}$ Program in Stem Cell Biology, Department of Pharmacology and Therapeutics, North Florida/South Georgia Veterans Health System, Gainesville, FL, USA and ${ }^{6}$ Pathology and Laboratory Medicine Service, North Florida/South Georgia Veterans Health System, Gainesville, FL, USA

Correspondence: Dr T Nakagawa, MD, PhD, Division of Nephrology, Hypertension and Transplantation, University of Florida, PO Box 100224, Gainesville, FL 32610-0224, USA. E-mail: nakagt@medicine.ufl.edu

Received 15 November 2007; revised 19 May 2008; accepted 25 May 2008
} 
Vascular endothelial growth factor (VEGF) plays a major pathophysiological role in diabetic nephropathy, ${ }^{12,13}$ despite VEGF exhibiting protective roles in nondiabetic renal disease. ${ }^{14,15}$ Recently, Celletti et al ${ }^{16}$ demonstrated that the deleterious effect of VEGF in the vascular system could be attributed to macrophage infiltration. We have recently reported that diabetic endothelial nitric oxide synthase (eNOS)-deficient mice develop advanced diabetic nephropathy, characterized by mesangial expansion, basement membrane thickening, mesangiolysis, glomerular microaneurysms and Kimmelstiel-Wilson-like nodules, all of which characterize human diabetic nephropathy. ${ }^{17}$ Interestingly, these advanced lesions were accompanied with an increase in renal VEGF expression, suggesting that uncoupling of VEGF with endothelial NO could provoke severe glomerular lesions (reviewed in Nakagawa ${ }^{18}$ ). Here, we examined the association of macrophage infiltration with VEGF in glomerular lesions of diabetic eNOS-deficient mice. Additionally, we further investigated a mechanism by which $\mathrm{NO}$ could potentially regulate macrophage migration in response to VEGF.

\section{MATERIALS AND METHODS Materials}

VEGF binds to VEGF receptor 1 (Flt-1) and VEGF receptor 2 (KDR). Plasmids with VEGF mutants that selectively bind to either KDR (KDR-sel) or Flt-1 (Flt-1-sel) were kindly provided by N Ferrara (Genentech Inc., South San Francisco, CA, USA). Other reagents included VEGF (R\&D Systems Inc. Minneapolis, MN, USA), DETA NONOate (Sigma, St Louis, MO, USA), 31169, a specific inhibitor of p38 MAP kinase (Scios Sunnyvalley, CA, USA) ${ }^{19}$ and Uo126, a specific inhibitor of ERK (New England Biolabs Inc., Beverly, MA, USA). Goat polyclonal antibody to VEGF (no. AF 564; R\&D Systems Inc.), rabbit monoclonal antibodies to Flt-1 (no. 1303; Epitomics, Burlingame, CA, USA) and rabbit monoclonal antibodies to KDR (no. 2479; Cell Signaling Technology, Beverly, MA, USA), rat anti-mouse antibody (no. 479R; Serotec, Raleigh, NC, USA) for F4/80, mouse monoclonal antibody for CD68 (no. 955, Abcam, Cambridge, MA, USA), mouse monoclonal ICAM-1 antibody (no. AF796; R\&D Systems Inc.) were used for immunofluorescence, immunohistochemistry and/or western blot. A monoclonal anti-glyceraldehyde-3-phosphate dehydrogenase (GAPDH) antibody was purchased from Chemicon (Temecula, CA, USA). Peroxidase-conjugated rabbit IgG and mouse IgG (Dako, Carpinteria, CA, USA) were used. FITC-conjugated rabbit anti-goat IgG and goat anti-rabbit IgG, Texas Red-conjugated goat anti-rat IgG and Texas $\operatorname{Red}^{\mathbb{R}}-\mathrm{X}$ phalloidin were from Invitrogen (Carlsbad, CA, USA).

\section{Experimental Animals}

Experiments were approved by the Animal Care and Use Committee of the University of Florida. C57Bl/6J (C57BL/6) and C57BL/6J-Nos3tm1Unc (eNOS knockout (KO) mice) (Jackson Laboratory, Bar Harbor, ME, USA) aged 8 weeks were rendered diabetic with intraperitoneal injections of streptozotocin (STZ, $100 \mathrm{mg}$ per kg per day for 2 consecutive days) freshly dissolved in citrate buffer ( $\mathrm{pH} 4.5)$. Development of diabetes (defined by blood glucose greater than $250 \mathrm{mg}$ per $100 \mathrm{ml}$ ) was verified 1 week after the first STZ injection using the One Touch system (Johnson\&Johnson, Milpitas, CA, USA). For blood sugar control, a single insulin pellet (Linshin Canada Inc., ON, Canada) was implanted subcutaneously for 3 months. Mice were housed in the animal care facility with $12 \mathrm{~h}$ light/dark cycle and allowed free access to food and water. Body weight was recorded monthly. At 3 months, mice were euthanized for histological analysis. Six groups, which were nondiabetic, diabetic and diabetes with insulin treatment in wild-type mice and eNOS $\mathrm{KO}$ mice (each group contains six mice), were examined. Systolic blood pressure was assessed as the mean value of three consecutive measurements obtained in the morning using a tail-cuff sphygmomanometer (Visitech BP2000; Visitech Systems Inc., Apex, NC, USA). BUN was measured by BUN assay (Diagnostic Chemicals Limited, PE, Canada).

\section{Renal Histology and Immunohistochemistry}

Kidneys were fixed in 10\% formalin solution or Fekete's fixative $(70 \mathrm{ml}$ of $100 \%$ ethanol, $30 \mathrm{ml}$ of distilled water, $10 \mathrm{ml}$ of $37 \%$ formalin, $5 \mathrm{ml}$ of glacial acetic acid), and embedded in paraffin. Alternatively, kidneys were frozen in OCT compound (Sakura Finetek USA Inc., Torrance, CA, USA) and kept frozen at $-80^{\circ} \mathrm{C}$ until use. Sections $(2 \mu \mathrm{m})$ were stained with the periodic acid-Schiff reagent and counterstained with hematoxylin. Percent numbers of injured glomeruli (mesangiolysis, mesangial expansion and nodular lesions) in the kidney in each group of control mice and diabetic mice was quantified by two independent investigators. Indirect immunoperoxidase staining was performed using antibodies to VEGF, Flt-1, KDR and F4/80. Immunostaining for CD68 was performed on frozen kidney. Color was developed using diaminobenzidine as a chromogen. Macrophage infiltration was quantified by two independent investigators on the 30 glomeruli per each slide under a microscope at $\times 400$ magnification. As macrophage formed clusters in which it is hard to identify a number of cells, staining area was revealed as percent positive area for F4/80 or CD68. Glomerular VEGF and ICAM-1 expressions were measured as percent positive area in glomerulus with 50 glomeruli per animals. For the double immunofluorescence staining with VEGF receptors (VEGFRs; Flt-1 and KDR) and macrophages, $4-\mu \mathrm{m}$ sections of frozen kidney were fixed in acetone. The sections were first stained with antibodies to VEGFRs (Flt-1 or KDR), followed by incubation with FITCconjugated secondary antibodies (anti-goat IgG or antirabbit IgG). They were then incubated with a monoclonal rat anti-mouse monocyte-macrophage marker F4/80, followed 
by incubation with Texas Red-conjugated goat anti-rat IgG. All of the sections were covered with Vectashield ${ }^{\mathbb{R}}$ with DAPI (Vector Laboratories Inc., Burlingame, CA, USA) and were examined by epifluorescence microscopy using the Axiovert 200 M (Carl Zeiss, Jena, Germany).

\section{Cell Culture}

Rat glomerular endothelial cells (GECs) were used as positive control for VEGFRs, and were kindly provided by S Adler (New York Medical College, Valhalla, NY, USA). A mouse macrophage cell line (RAW 264.7; ATCC, Manassas, VA, USA) was cultured in DMEM, containing $10 \%$ fetal bovine serum (FBS) and 100 units per $\mathrm{ml}$ penicillin, $100 \mu \mathrm{g} / \mathrm{ml}$ streptomycin (Gibco Brl, Gaithersburg, MD, USA). Subconfluent macrophages were incubated in serum-free medium for $16 \mathrm{~h}$ to arrest and synchronize cell growth. After this period, the medium was changed to fresh serum-free DMEM containing $10 \mathrm{ng} / \mathrm{ml} \mathrm{VEGF} \mathrm{and} 10^{-4} \mathrm{M}$ DETA NONOate for up to $24 \mathrm{~h}$. This concentration of DETA NONOate has been proven to reveal no toxicity on macrophage. ${ }^{16}$ All experiments were repeated at least three times.

\section{Selective Stimulation of KDR and Flt-1}

Transient transfection of the expression vectors for KDR-sel, Flt-1-sel and VEGF were performed in NRK cells (ATCC) using $2.0 \mu \mathrm{g}$ of DNA with the Lipofectamine Plustm Reagent kit (Gibco Brl, Grand Island, NY, USA). Cells were maintained in DMEM with $10 \%$ serum for $24 \mathrm{~h}$ after transfection. VEGF concentration in culture media of NRK cells was examined with the human VEGF ELISA kit (R\&D Systems Inc.). Then, RAW-264.7 cells were stimulated with NRK culture media containing $1 \mathrm{ng} / \mathrm{ml} \mathrm{KDR-sel,} \mathrm{Flt-1-sel} \mathrm{or} \mathrm{VEGF.}$

\section{Cell Migration Assay}

The migration of macrophages was assayed by a modification of the Boyden chamber method using Transwell chambers (Costar, Cambridge, MA, USA) with pores of $5.0-\mu \mathrm{m}$ diameter. Aliquots of $1.0 \times 10^{5}$ cells per $\mathrm{ml}$ in DMEM medium containing $10 \%$ FBS $(100 \mu \mathrm{l})$ were placed in the upper chamber. Then, $600 \mu \mathrm{l}$ of DMEM medium containing $10 \%$ FBS and VEGF $(10 \mathrm{ng} / \mathrm{ml})$, KDR-sel $(10 \mathrm{ng} / \mathrm{ml})$, Flt-1-sel $(10 \mathrm{ng} / \mathrm{ml})$, DETA NONOate $\left(10^{-4} \mathrm{M}\right), 31169\left(10^{-5} \mathrm{M}\right)$ and/or Uo126 $\left(10^{-5} \mathrm{M}\right)$ was placed in the lower chamber. A cellulose acetate membrane filter was interposed between the two chambers. The chambers were kept in a humidified atmosphere of $5 \% \mathrm{CO}_{2}$ at $37^{\circ} \mathrm{C}$ for $2 \mathrm{~h}$. Filters were subsequently fixed with methanol and stained with hematoxylin. The number of cells that migrated into the filter and completely reached the lower side was determined microscopically. All assays were performed in replicate four times. The migration activity was blindly quantified by counting of the migrated cells on the lower surface of the membrane of 16 fields per chamber.

\section{Cell Hypertrophy}

After preincubation with DMEM containing 10\% FCS at $37^{\circ} \mathrm{C}$ for $2 \mathrm{~h}$, macrophage were stimulated with DETA NONOate $\left(10^{-4} \mathrm{M}\right)$, VEGF $(10 \mathrm{ng} / \mathrm{ml})$, Flt-1-sel $(10 \mathrm{ng} / \mathrm{ml})$ and/or KDR-sel $(10 \mathrm{ng} / \mathrm{ml})$ for $30 \mathrm{~min}$. In some experiments, cells were pretreated with $31169\left(10^{-5} \mathrm{M}\right)$ or $\operatorname{Uo126}\left(10^{-5} \mathrm{M}\right)$ prior to stimulations. Cells were fixed with $3.7 \%$ formaldehyde and permeabilized with $0.1 \%$ Triton X-100 in PBS before nonspecific binding sites were blocked with $1 \%$ BSA and $10 \%$ skim milk in PBS. Using detection of F-actin with Texas $\operatorname{Red}^{\mathbb{R}}$-X phalloidin, cell size was analyzed with AxioVision Rel. 4.4 software (Carl Zeiss).

\section{Real-Time PCR}

To quantify mRNA expression for VEGF, Flt-1, KDR, nNOS and inducible NO synthase (iNOS), we performed real-time PCR as described previously. ${ }^{17}$ Briefly, after $1 \mu \mathrm{g}$ of total RNA was converted to cDNA with iScript cDNA Synthesis kit (Bio-Rad, Hercules, CA, USA), PCR was performed as follows: $94^{\circ} \mathrm{C}$ for $5 \mathrm{~min}$, then 50 cycles of denaturation at $94^{\circ} \mathrm{C}$ for $30 \mathrm{~s}$, annealing at $64^{\circ} \mathrm{C}$ for $30 \mathrm{~s}$ and extension at $72^{\circ} \mathrm{C}$ for $60 \mathrm{~s}$. The sizes of amplicons were $189 \mathrm{bp}$ (mouse iNOS and mouse nNOS), 111 bp (mouse VEGF), 115 bp (mouse Flt-1), $115 \mathrm{bp}$ (mouse KDR) and 54 bp (mouse GAPDH) (Table 1). Specificity of amplification and absence of primer dimer was confirmed by melting curve analysis at the end of each run. Reaction specificity was also confirmed by electrophoretic analysis of products in 2\% agarose gel after real-time RT-PCR to check if bands of expected size were detected. Ratios to GAPDH mRNA were calculated for each sample and expressed as mean \pm s.d. All experiments were repeated at least three times.

\section{Western Blot Analysis}

As described previously, ${ }^{20} 20 \mu \mathrm{g}$ of cell protein samples were mixed with sample buffer (Sigma), boiled, resolved on 7.5\% Tris-HCl Ready Gel (Bio-Rad), and transferred to PVDF membranes by electroblotting. Membranes were blocked with $5 \%(\mathrm{wt} / \mathrm{vol})$ dry fat-free milk in PBS with $0.1 \%$ Tween (TBST) for $60 \mathrm{~min}$ at room temperature. Each primary antibody was incubated at $4^{\circ} \mathrm{C}$ overnight. After washing with PBST, membrane was rocked with secondary antibody (anti-mouse IgG or anti-rabbit IgG, HRP-linked antibody) for $60 \mathrm{~min}$ at room temperature. The blot was then developed using the ECL Plus detection kit (Amersham International, Bucks, UK) to produce a chemiluminescence signal, which was captured on X-ray film. The density of each band was measured using FluoChem (Alpha Innotech, San Leandro, CA, USA). All experiments were repeated at least three times.

\section{Statistical Analysis}

All values presented are expressed as mean \pm s.d. Statistical analysis was performed with unpaired, two-tailed Student's 
$t$-tests for single comparisons or ANOVA for multiple comparisons. A $P$-value of $<0.05$ was considered significantly different.

Table 1 Gene-specific nucleotide sequences used for PCR and real-time PCR

$\begin{array}{ll}\text { Mouse VEGF-A (111 bp) } & \\ \text { Forward } & \text { 5'-CCAGCGAAGCTACTGCCGTCCA-3' } \\ \text { Reverse } & \text { 5'-ACAGCGCATCAGCGGCACAC-3' }\end{array}$

Mouse Flt-1(115bp)

Forward

5'-GAGGAGGATGAGGGTGTCTATAGGT-3'

Reverse

5'-GTGATCAGCTCCAGGTTGACTT-3'

Mouse KDR (115 bp)

Forward

5'-GCCCTGCTGTGGTCTCACTAC-3'

Reverse

5'-CAAAGCATTGCCCATTCGAT-3'

Mouse iNOS (189 bp)

Forward

5'-CTCTGACAGCCCAGAGTTCC-3'

Reverse

5'-GAAAGGGAGAGAGGGGAGG-3'

Mouse nNOS (189 bp)

Forward

5'-AAGGAGCAAGGAGGCCATAT-3'

Reverse

5'-ATATGTTCTGAGGGTGACCCC-3'

Mouse GAPDH (54 bp)

Forward

5'-CATGGCCTTCCGTGTTCCTA-3'

Reverse

$5^{\prime}$-GCGGCACGTCAGATCCA-3'

GAPDH, glyceraldehyde-3-phosphate dehydrogenase; iNOS, inducible NO synthase; VEGF, vascular endothelial growth factor.

\section{RESULTS}

As shown in Table 2, STZ injection induced diabetes in both C57BL/6 and eNOS KO mice. Loss of body weight occurred in all diabetic mice, compatible with previous reports. ${ }^{21}$ Systolic blood pressure was higher in eNOS KO mice compared to C57BL/6 under either nondiabetic or diabetic condition although diabetes raised systolic blood pressure in both mice. In addition, diabetes-induced renal dysfunction was striking in eNOS KO mice compared to C57BL/6. However, insulin treatment controlled blood glucose for 3 months and prevented these abnormalities induced by diabetic condition.

\section{The Association of Glomerular Injuries with Macrophage Infiltration in Diabetic eNOS Knockout Mice}

As shown in Figure 1a, diabetic eNOS KO mice developed a variety of glomerular injuries, such as mesangial expansion (b), mesangiolysis (c), glomerular microaneurysm (d) and nodular glomerulosclerosis (e), all of which resemble human diabetic nephropathy. ${ }^{22,23}$ Glomerular injury was significantly greater ( $15 \%$ of glomeruli) in diabetic eNOS KO mice compared to diabetic C57BL/6 mice (5\% of glomeruli) (Figure 2a). Insulin treatment blocked glomerular injury in wild-type as well as in eNOS KO mice. Although F4/80 macrophages were predominantly observed in the tubulointerstitium in the diabetic condition, a small number of these cells also were present in glomeruli. On the other hand, CD68 macrophages were predominantly present in glomeruli. Interestingly, both CD68 and F4/80 macrophage infiltration in glomeruli were significantly increased in diabetic eNOS KO mice compared to diabetic wild-type mice. The macrophage infiltration was blocked by insulin treatment in both types of mice (Figure $2 \mathrm{~b}$ and $\mathrm{c}$ ). In addition, other markers of inflammation, such as ICAM-1, were also induced by the diabetic condition, and were prevented by insulin treatment (Figure 2d).

Table 2 Blood sugar, body weight, blood pressure and blood urea nitrogen at 3 months

\begin{tabular}{|c|c|c|c|c|c|c|}
\hline & \multicolumn{2}{|c|}{ Control } & \multicolumn{2}{|c|}{ DM } & \multicolumn{2}{|c|}{ DM+insulin } \\
\hline & C57BL/6 & eNOS KO & C57BL/6 & eNOS KO & C57BL/6 & eNOS KO \\
\hline BS (mg per $100 \mathrm{ml}$ ) & $113 \pm 20$ & $108 \pm 13$ & $349 \pm 118$ & $351 \pm 111$ & $95 \pm 36$ & $127 \pm 71$ \\
\hline BW (g) & $30.0 \pm 0.8$ & $29.0 \pm 1.0$ & $24.3 \pm 1.5$ & $19.3 \pm 2.1^{\mathrm{a}}$ & $26.7 \pm 1.6$ & $24.8 \pm 1.7$ \\
\hline $\mathrm{BP}(\mathrm{mm} \mathrm{Hg})$ & $124 \pm 7$ & $137 \pm 8^{b}$ & $140 \pm 13$ & $167 \pm 15^{c}$ & $125 \pm 7$ & $141 \pm 12^{b}$ \\
\hline
\end{tabular}

BS, blood sugar; BW, body weight; BP, blood pressure; BUN, blood urea nitrogen; DM, diabetic mice; eNOS KO, endothelial nitric oxide synthase knockout.

${ }^{\mathrm{a}} P<0.001$ vs diabetic C57BL/6 mice.

$\mathrm{b}_{P<0.01 \text { vs control C57BL/6 mice. }}$

${ }^{\mathrm{c}} P<0.01$ vs diabetic C57BL/6 mice.

$\mathrm{d}_{P<0.05 \text { vs diabetic } \text { C57BL/6 mice. }}$

Values are means \pm s.d.; $n=6$ /group. 


\section{VEGF and VEGFRs are Associated with Macrophage Infiltration in Diabetic eNOS Knockout Mice}

As VEGF plays a pathophysiological role in diabetic nephropathy, and has also been shown to mediate macrophage infiltration in other conditions, we determined if VEGF was associated with macrophage infiltration. VEGF mRNA expression in whole kidney was induced in diabetes in C57BL/6 as well as in eNOS KO mice (Figure 3A). Diabetic glomeruli quantitatively had increased VEGF protein expression, which was also inhibited by insulin treatment (Figure 3B). Interestingly, VEGF protein was restricted to glomerular podocytes in both diabetic C57BL/6 and diabetic eNOS KO mice and expression was maintained even in severely injured glomeruli (Figure 3C).

To identify if intraglomerular macrophages express VEGFRs, double immunostaining for F4/80 and VEGFRs was performed in diabetic eNOS $\mathrm{KO}$ mice. Interestingly, some F4/80-positive macrophages expressed Flt-1 in both the glomeruli (Figure 3D). Furthermore, we examined the correlation between macrophage infiltration and VEGF expression in glomeruli in both types of mice. Both F4/80- and CD68-positive macrophages were positively associated with glomerular VEGF expression (Figure 3D-F). Interestingly, the VEGF association was stronger with only eNOS KO mice for both F4/80 $\left(R^{2}=0.80\right)$ and CD68 $\left(R^{2}=0.83\right)$.

\section{The Renal Expression of iNOS and nNOS in Diabetic eNOS Knockout Mice}

PCR demonstrated that mouse kidney expressed both iNOS and nNOS (Figure 4). Quantitative analysis with real-time PCR revealed that there was no different in iNOS or nNOS expression in C57BL/6 and eNOS KO mice. Likewise, no differences in expression were observed in wild-type $v s$ eNOS $\mathrm{KO}$ mice in the diabetic condition (Figure $4 \mathrm{~b}$ and c). These data indicated that nNOS and iNOS expressions are unlikely to explain the differences in macrophage infiltration observed between eNOS KO and wild-type diabetic mice.

\section{Macrophage Phenotype}

We next examined the expression of VEGFRs and NOS in a macrophage cell line (RAW 264.7). Although both Flt-1 and KDR mRNA expressions were detected, Flt-1 was predominant in this cell (Figure 5a). Compatibly, macrophages expressed abundant Flt-1 protein similar to that observed in GECs. On the other hand KDR protein could not be detected (Figure $5 b$ ). With respect to NOS expression, the macrophage cell line did not possess eNOS (Figure 5c), but expressed iNOS (Figure 5d) that was neither activated nor upregulated by VEGF (data not shown), suggesting that macrophages did not produce NO in response to VEGF.

\section{Macrophage Migration is Induced by VEGF and Inhibited by NO}

We next examined if exogenous NO could prevent macrophage migration in response to VEGF. Macrophage migration was induced by $10 \mathrm{ng} / \mathrm{ml}$ VEGF and inhibited by $10^{-4} \mathrm{M}$ NONOate at $2 \mathrm{~h}$ (Figure 6A). VEGF induced macrophage migration in a dose-dependent manner (Figure 6B) whereas NONOate inhibited it in a dose-dependent manner (Figure 6C). Importantly, macrophage migration in response to VEGF was significantly blocked by the exogenous NO donor (Figure 6D).

Cell migration is a complex phenomenon that requires cytoskeleton-regulated cell motility and cell adhesion, and actin reorganization is essential for cell motility. Therefore, we examined the effect of exogenous $\mathrm{NO}$ on cell spreading as revealed by cell size in response to VEGF. VEGF-induced cell hypertrophy was also blocked in the presence of $\mathrm{NO}$ (Figure 6E).

\section{Flt-1 is Responsible for VEGF-Induced Macrophage Migration}

To identify the role of VEGFRs on macrophage migration, cells were stimulated by two kinds of VEGF mutants, one that selectively binds to Flt-1 (Flt1-sel) and the other that is specific for KDR (KDR-sel). ${ }^{24}$ As shown in Figure 7, Flt1-sel VEGF significantly induced macrophage migration and was equivalent to that observed with VEGF whereas migration number with KDR-sel VEGF had no effect (Figure 7a). Similarly, cell size was increased with stimulation by Flt-1-sel VEGF, but not with the KDR-sel VEGF mutant (Figure $7 \mathrm{~b}$ ).

The level of Flt- 1 expression peaked at $2 \mathrm{~h}$ after stimulation with VEGF (Figure 7c) whereas KDR expression was not stimulated by VEGF (data not shown). Interestingly, exogenous NO negatively downregulated Flt-1 protein expression at $2 \mathrm{~h}$ (Figure $7 \mathrm{~d}$ and e) and Flt-1 mRNA expression at $30 \mathrm{~min}$ (Figure $7 \mathrm{f}$ ).

\section{Flt-1-Mediated Macrophage Migration is Dependent on p38 MAP Kinase}

Macrophage migration in response to VEGF was blocked by 31169 (a specific inhibitor of p38 MAP kinase), but not by Uo126 (a specific inhibitor of ERK) (Figure 8a). Similarly, VEGF-induced cell hypertrophy was blocked by the p38 inhibitor (Figure 8b).

\section{DISCUSSION}

Diabetic nephropathy remains the most common cause of end-stage renal disease worldwide. Experimental animal models that resemble human diabetic nephropathy have been lacking. ${ }^{25}$ Recently our group ${ }^{17}$ and others ${ }^{26}$ have shown that a form of diabetes that can rapidly induce all of the stages of human diabetic nephropathy occurs in genetically altered mice with severe endothelial dysfunction owing to lack of eNOS. This model therefore provides a unique ability to evaluate mechanisms of renal injury that may be applicable to the human diabetic condition.

In this paper we have evaluated the role of endothelial dysfunction in the inflammatory component of diabetic 
A
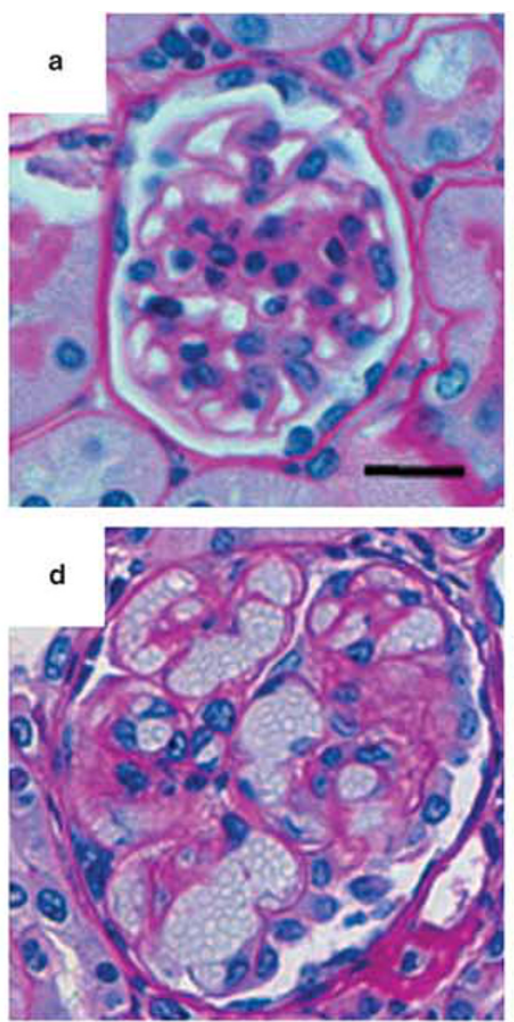
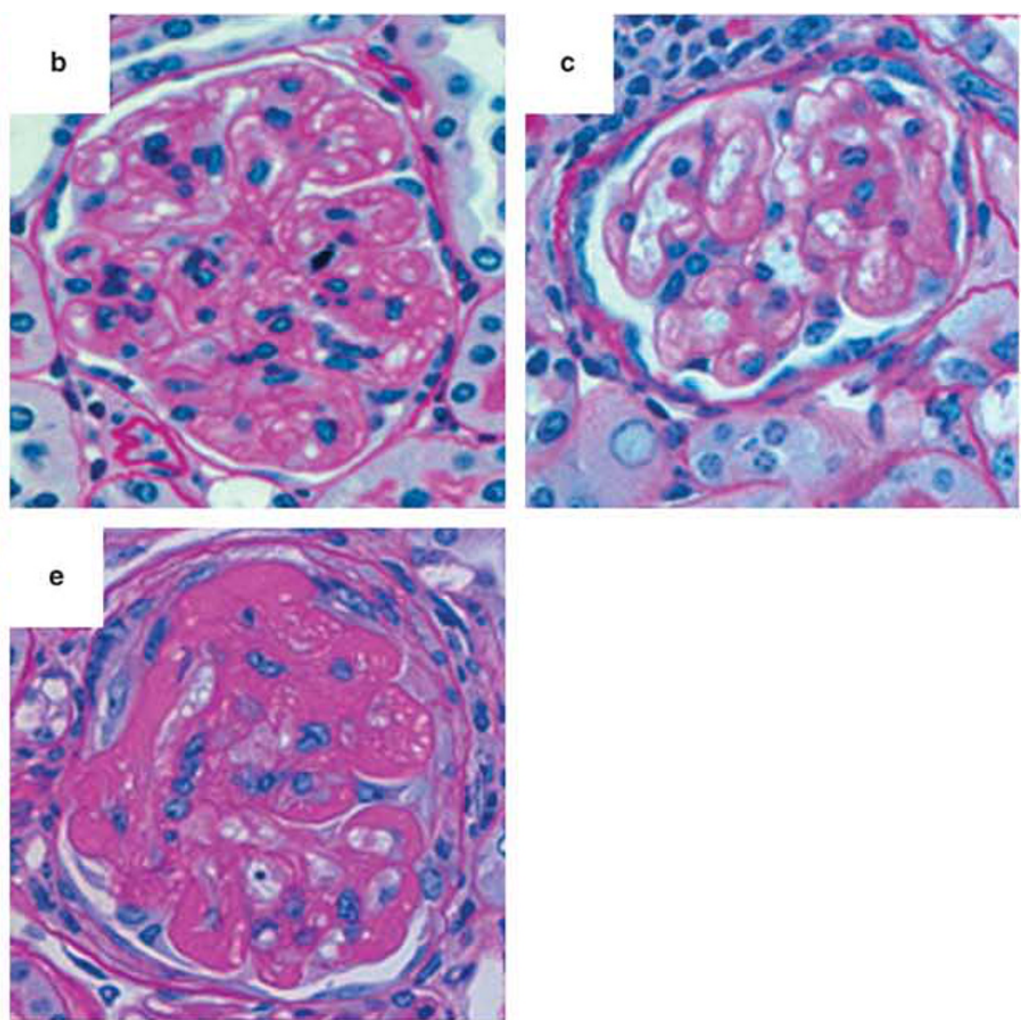

B
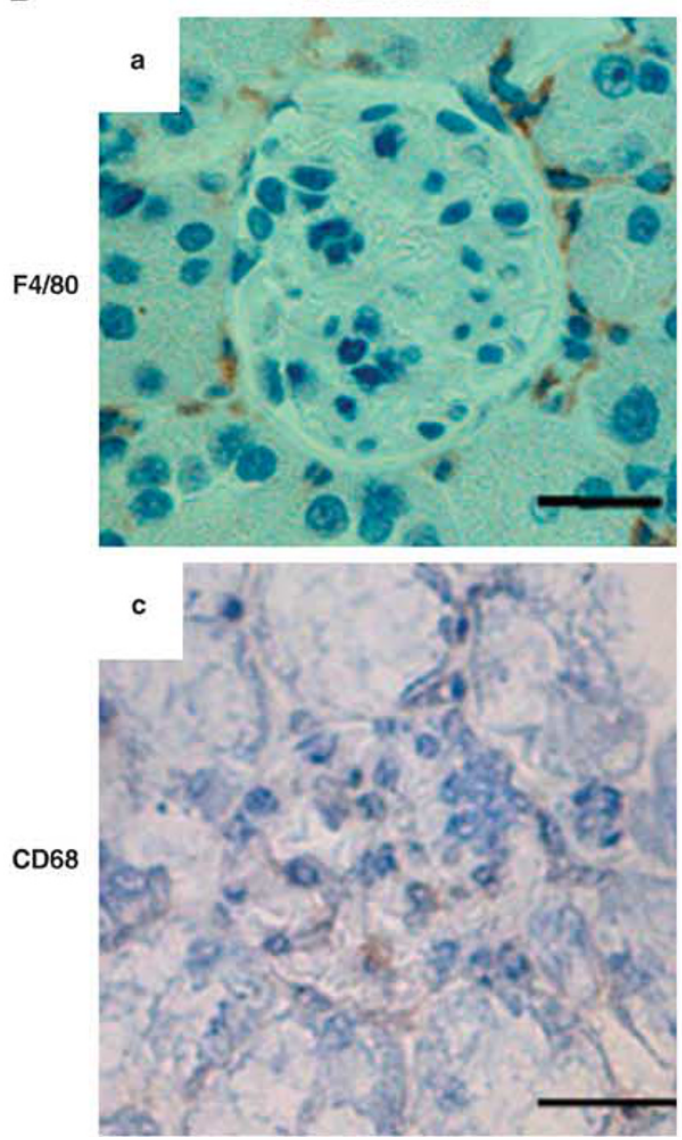

DM ENOSKO
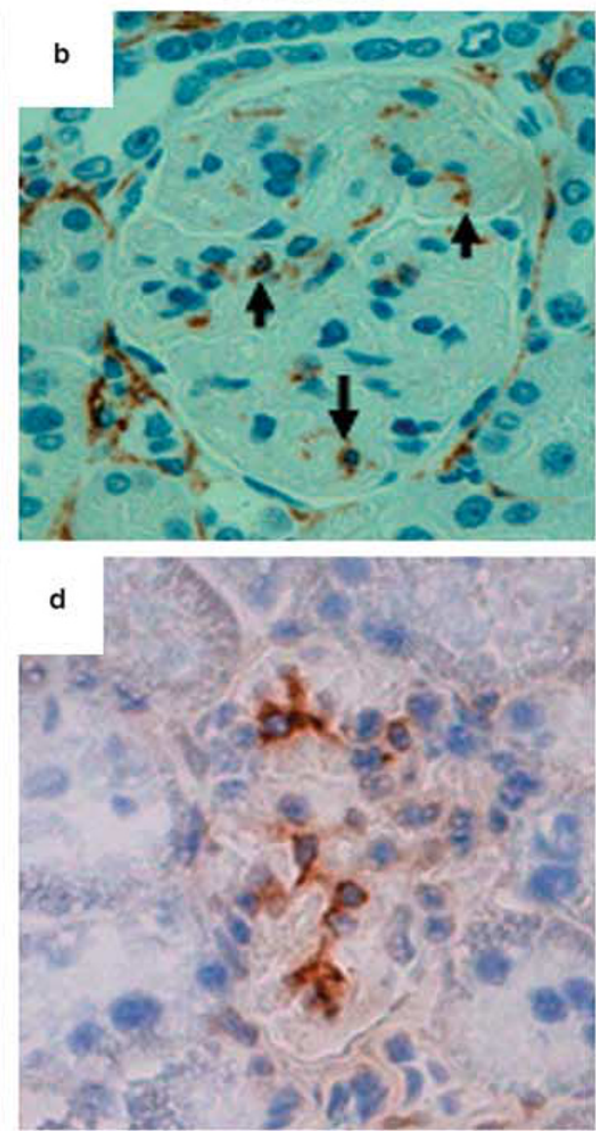
nephropathy. Although diabetic nephropathy is not often considered an inflammatory disease, ${ }^{1}$ there is strong evidence that macrophage infiltration not only is increased but may have a role in mediating local injury (mesangiolysis) and fibrosis. ${ }^{3-5,7}$ Our hypothesis was that a state of endothelial dysfunction might result in greater macrophage infiltration or activation. In this regard, we obtained several important new findings. First, we demonstrated that macrophage infiltration was greater in eNOS KO $v s$ wild-type diabetic mice. Second, there is a positive correlation between VEGF expression and macrophage infiltration in glomeruli in these models. We also found that a decrease in VEGF expression in response to insulin was associated with a reduction of macrophage infiltration in glomerulus. Third, we provide evidence that the accumulation of macrophages might result in part from response to an increased expression of VEGF in podocytes. This assertion is supported by the evidence that the macrophages express Flt-1 in association with podocyte expression of VEGF. Furthermore, our in vitro study demonstrated that VEGF or the Flt-1-sel VEGF mutant could stimulate macrophage infiltration and hypertrophy in vitro. Most importantly, we demonstrated that the mechanism by which NO can negatively regulate VEGF-induced macrophage infiltration is by reducing Flt-1 expression. Thus, these studies suggest that severe endothelial dysfunction and a poor endothelial NO response can lead to greater VEGF-mediated macrophage infiltration and activation. In the setting where VEGF and endothelial NO are uncoupled,
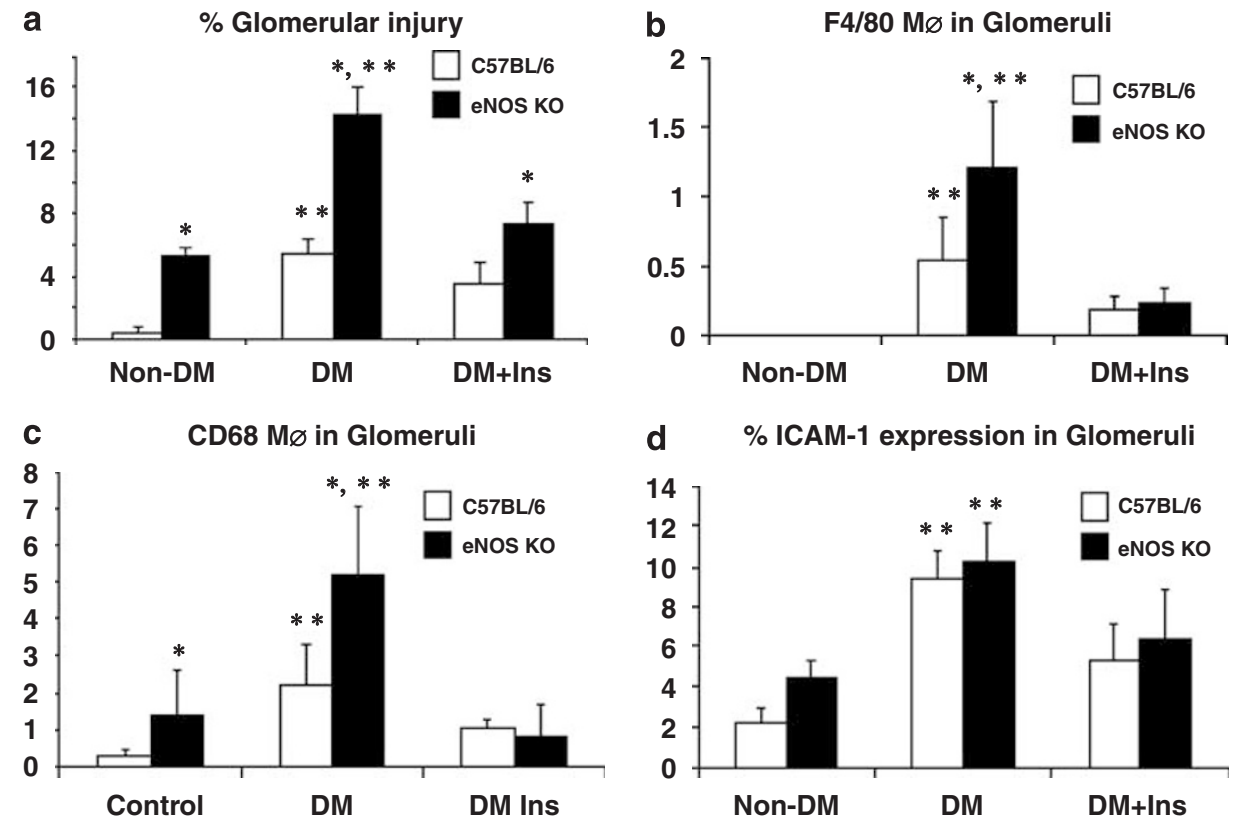

Figure 2 Quantification of glomerular injury, macrophage infiltration and ICAM-1 expression in glomerulus. (a) Glomerular injury in diabetic C57BL/6 and eNOS knockout (KO) mice at 3 months. The graph summarizes of the percent of injured glomeruli, including mesangial expansion, mesangiolysis, glomerular microaneurysm and nodular lesions in C57BL/6 diabetic mice and diabetic eNOS KO mice. Diabetic condition (DM) causes glomerular injury in both types of mice whereas eNOS KO mice exhibit severe injuries. Insulin treatment (DM + Ins) blocked diabetes-induced glomerular injury. (b) Glomerular F4/80 macrophage infiltration in diabetic eNOS KO and wild-type mice as revealed by percent positive staining in glomerulus. Although diabetes significantly induces F4/80 macrophage infiltration, eNOS KO mice exhibit more increased infiltration. (c) Glomerular CD68 macrophage infiltration in diabetic eNOS KO and wild-type mice as revealed by percent positive staining in glomerulus. CD68 macrophage is infiltrated into glomerulus in diabetic condition, but eNOS deficiency enhanced CD68 macrophage infiltration. However, it was blocked by insulin treatment. (d) Glomerular ICAM-1 expression is also induced by diabetic condition, and this increase is prevented by insulin treatment. ${ }^{*} P<0.01$ vs wild-type in the same diabetic condition. ${ }^{* * P}<0.01$ vs nondiabetes or $\mathrm{DM}+$ Ins treatment in the same specie.

Figure 1 Glomerular injury and macrophage infiltration in diabetic eNOS knockout (KO) mice. (A) By periodic acid-Schiff (PAS) staining, diabetic eNOS KO mice exhibit a variety of glomerular injuries, such as mesangial expansion (b), mesangiolysis (c), glomerular microaneurysm (d) and nodular lesion (e) compared with diabetic C57BL/6 mice (a). Bar, $10 \mu \mathrm{m}$. (B) Immunohistochemistry for glomerular macrophages. Brown color (arrow) indicates F4/80 macrophage, which is rare in glomeruli of nondiabetic C57BL/6 mice (a) whereas a couple of positive cells are observed in glomerulus of diabetic eNOS KO mice (b). Similarly, CD68 macrophage is not present in glomerulus of nondiabetic wild-type mice (c). However, diabetic eNOS KO mice have a couple of CD68 macrophage (brown color) in glomerulus (d). Bar, $10 \mu \mathrm{m}$. 


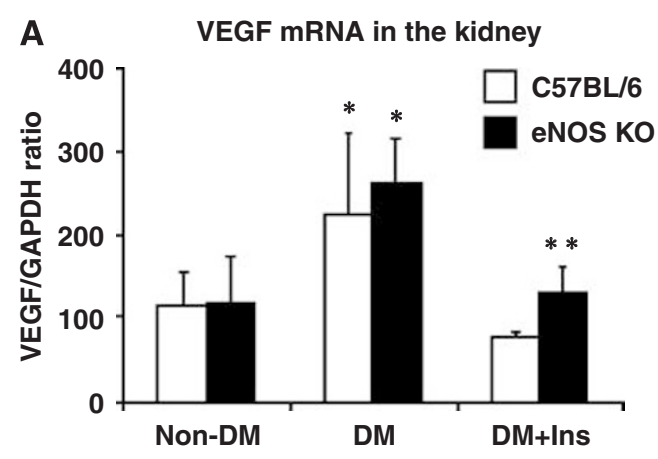

C
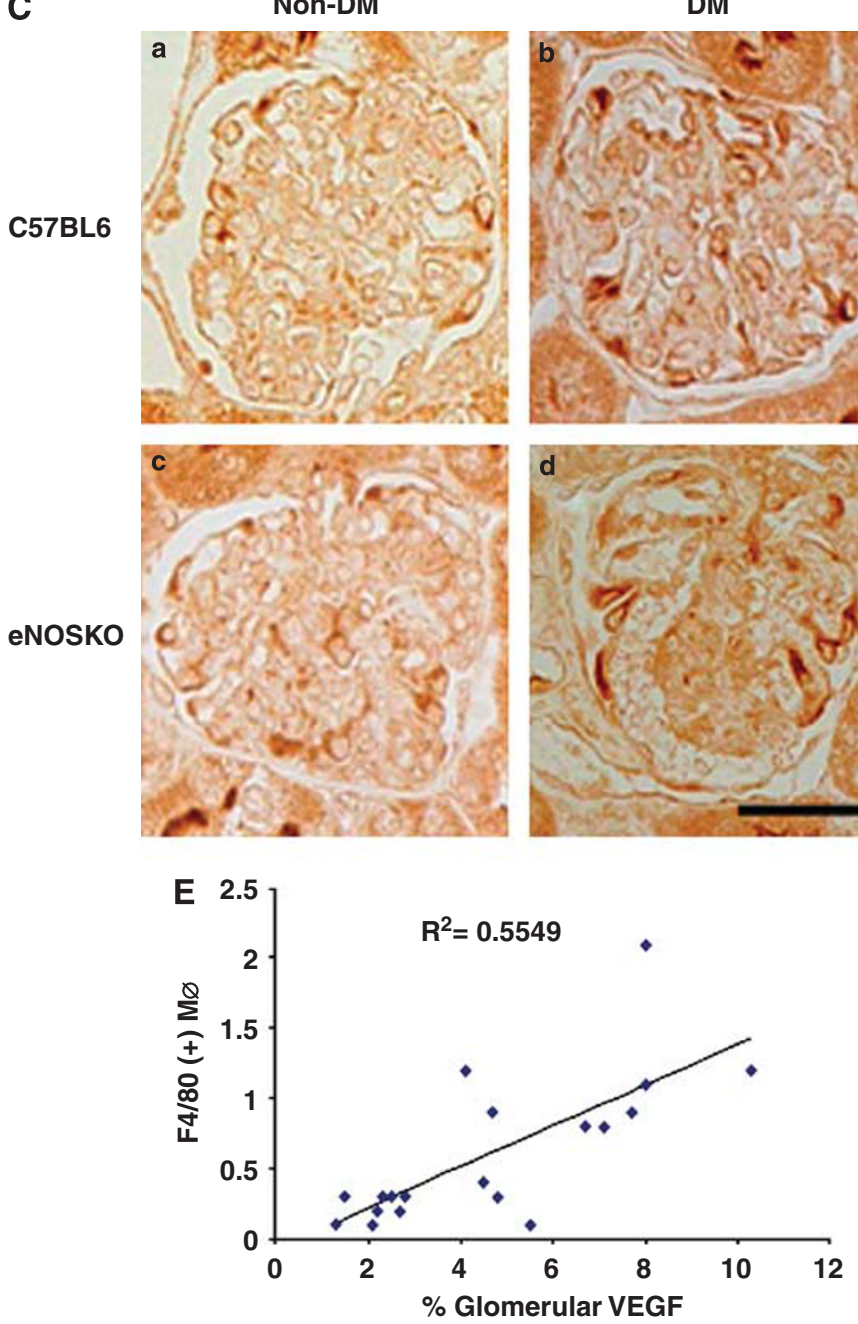

B VEGF protein in the glomerulus

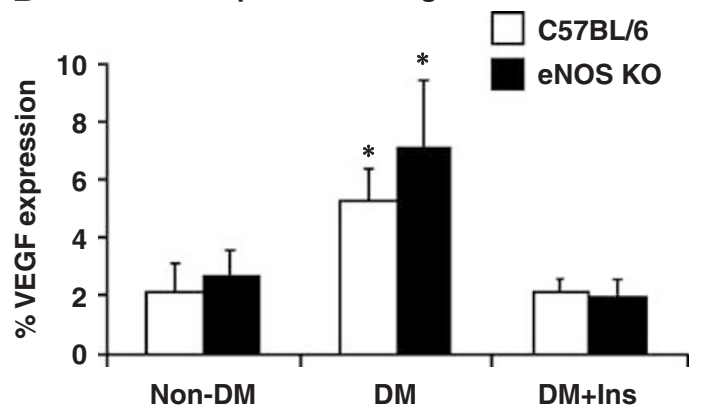

D
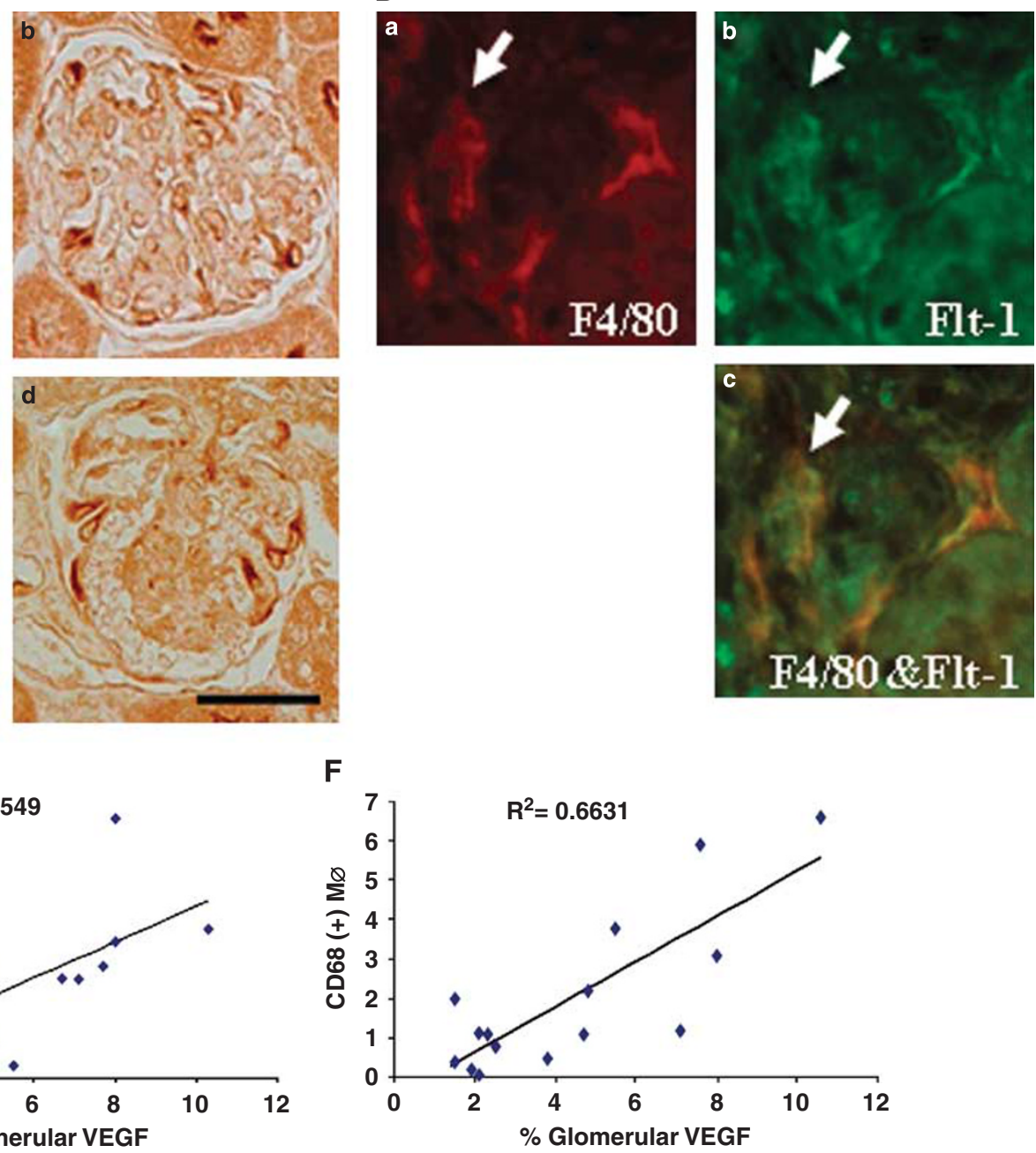

Figure 3 The expression of VEGF, Flt-1 and KDR on diabetic eNOS knockout (KO) mice. (A) Renal VEGF mRNA expression in diabetic eNOS KO mice. There is no different in VEGF mRNA expression in whole kidneys between C57BL/6 and eNOS KO mice. Diabetes-induced VEGF expression is similar in eNOS KO mice and C57BL/6 wild-type mice. ${ }^{\star} P<0.01$ vs nondiabetes or $\mathrm{DM}+$ insulin treatment in the same species. ${ }^{*} P<0.01$ vs wild type in DM + insulin condition. (B) Quantification of glomerular VEGF immunoreactivity. VEGF expression is revealed as percent positive area in a glomerulus. ${ }^{*} P<0.01$ vs nondiabetes or $\mathrm{DM}+$ Insulin treatment in the same species. (C) Immunohistochemistry for VEGF. VEGF expression (brown) is observed in podocyte of nondiabetic C57BL/6 (a) and nondiabetic eNOS KO mice (c). Although diabetes did not change the location of VEGF expression, podocyte showed a stronger signal for VEGF in diabetic C57BL/6 (b) and diabetic eNOS KO mice with severe injury (d). Bar, $20 \mu \mathrm{m}$. (D) Double immunostaining for F4/80 (a marker of macrophage) and Flt-1 in a diabetic eNOS KO mice. Arrows indicate cells that are positive for both F4/80 and Flt-1. (a) F4/80 staining, (b) Flt-1 staining, (c) merge. Bar, $20 \mu \mathrm{m}$. (e) The association between F4/80-macrophage and VEGF expressions in glomerulus, $P<0.01(P=0.002)$. (f) The association between CD68 macrophage and VEGF expressions in glomerulus, $P<0.01(P=0.0001)$. 


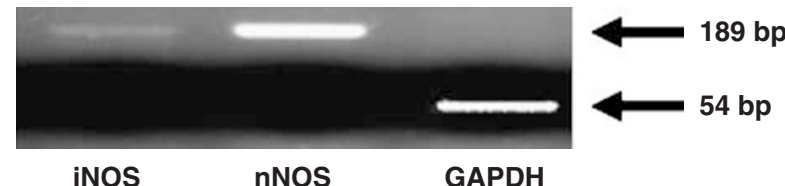

b

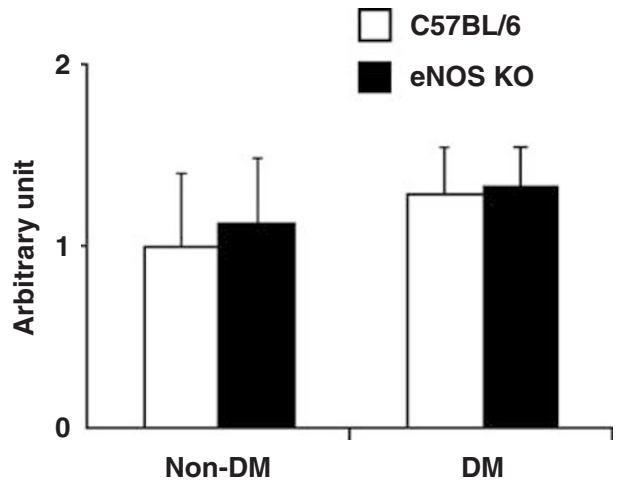

C

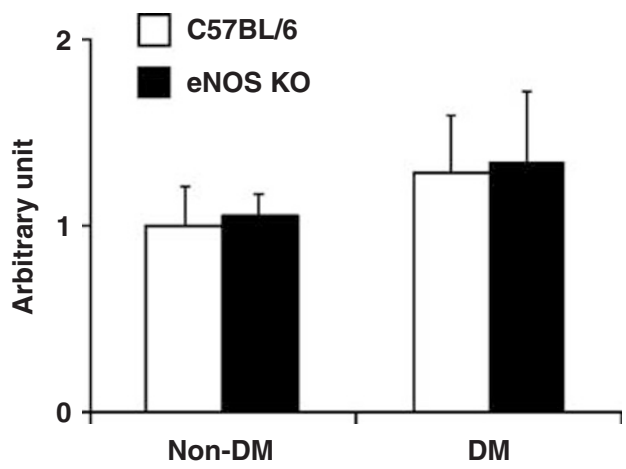

Figure 4 Renal expression of iNOS and nNOS mRNA in diabetic eNOS knockout (KO) mice. (a) iNOS and nNOS mRNA expressions in kidney of nondiabetic eNOS KO mice. Renal iNOS expression is less than nNOS in eNOS KO mice. (b) No difference in iNOS expression is observed between C57BL/6 and eNOS KO mice. iNOS expression is not induced by diabetic condition (DM) in these mice. (c) nNOS expression of eNOS KO mice is similar to that of C57BL/6 in both nondiabetic (non-DM) and diabetic conditions.

macrophage-mediated glomerular injury and fibrosis may become more severe.

One could argue that blocking VEGF is a way to test our hypothesis. However, blocking VEGF completely may inhibit normal kidney function. In fact, several groups have demonstrated that a major adverse effect of VEGF inhibition is renal injury. ${ }^{27}$ Given these facts, we chose to test our hypothesis by insulin treatment, which can reduce VEGF expression. As shown in Figure 3, insulin treatment blocked the induction of VEGF expression in the whole kidney as well as in the glomerulus. Importantly, insulin treatment blocked the macrophage infiltration (Figures $1 \mathrm{~b}, 2 \mathrm{~b}$ and $\mathrm{c}$ ) and glomerular injury in both wild-type and eNOS KO mice (Figure 2a). Furthermore, glomerular VEGF expression was positively correlated with glomerular macrophage infiltration a

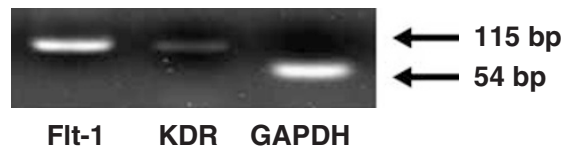

b

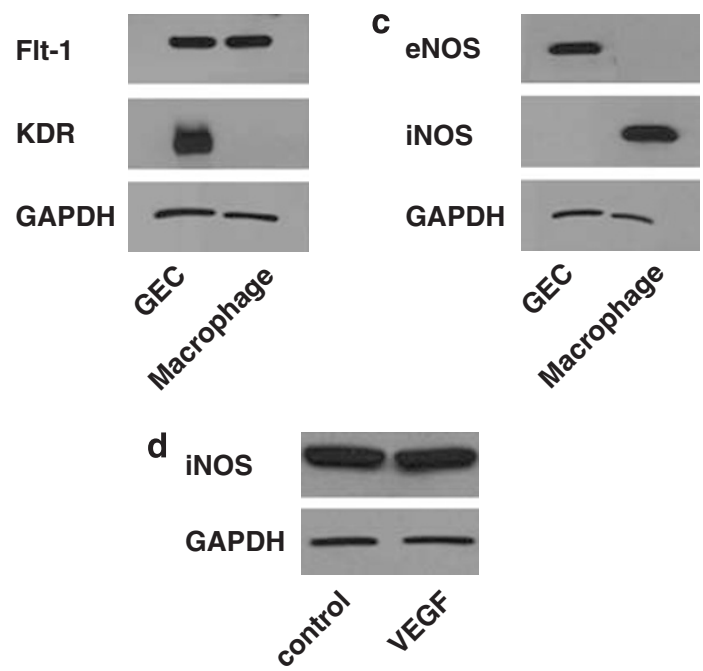

Figure 5 VEGF receptors and nitric oxide synthase (NOS) expression in a murine macrophage cell line (RAW 264.7). (a) Flt-1 and KDR mRNA expressions in macrophages by PCR. (b) Western blotting for Flt-1 and KDR protein in macrophages. (c) Western blotting for endothelial NOS (eNOS) and inducible NOS (iNOS) protein in macrophages. (d) Western blotting of iNOS expression on macrophage $2 \mathrm{~h}$ after stimulation by VEGF. Rat glomerular endothelial cells (GECs) were used as a positive control for VEGF receptors and eNOS.

(Figure 3D and $\mathrm{F}$ ). These data suggest that the macrophage infiltration is tightly linked with VEGF expression in this model.

Although it has been already reported that Flt-1 is associated with VEGF-induced macrophage migration, ${ }^{28}$ its precise molecular mechanism is still unknown. In this study, we found that VEGF upregulates macrophage Flt-1 expression. We also found that Flt-1 mediates an increase in cell size, which is essential for macrophage migration. These data suggest that the upregulation of Flt-1 could be crucial for VEGF-induced macrophage migration. In addition, although we demonstrated a role of p38 on VEGF-mediated macrophage migration, other groups also reported that the endothelial cell utilizes this pathway. ${ }^{29,30}$ Therefore, the p38 pathway could be critical for cell migration in response to VEGF in various several cell types.

We identified two phenotypically different macrophage populations in this model. Compatible with previous reports, CD68 macrophages were the dominant infiltrating macrophage within the glomerulus. F4/80 macrophages dominated in the tubulointerstitium, but in the diabetic condition these were also present in small numbers in glomeruli. Harris's group has also documented differing macrophage phenotypes. For example, his group demonstrated that one phenotype of macrophage is associated with proinflammatory 
A
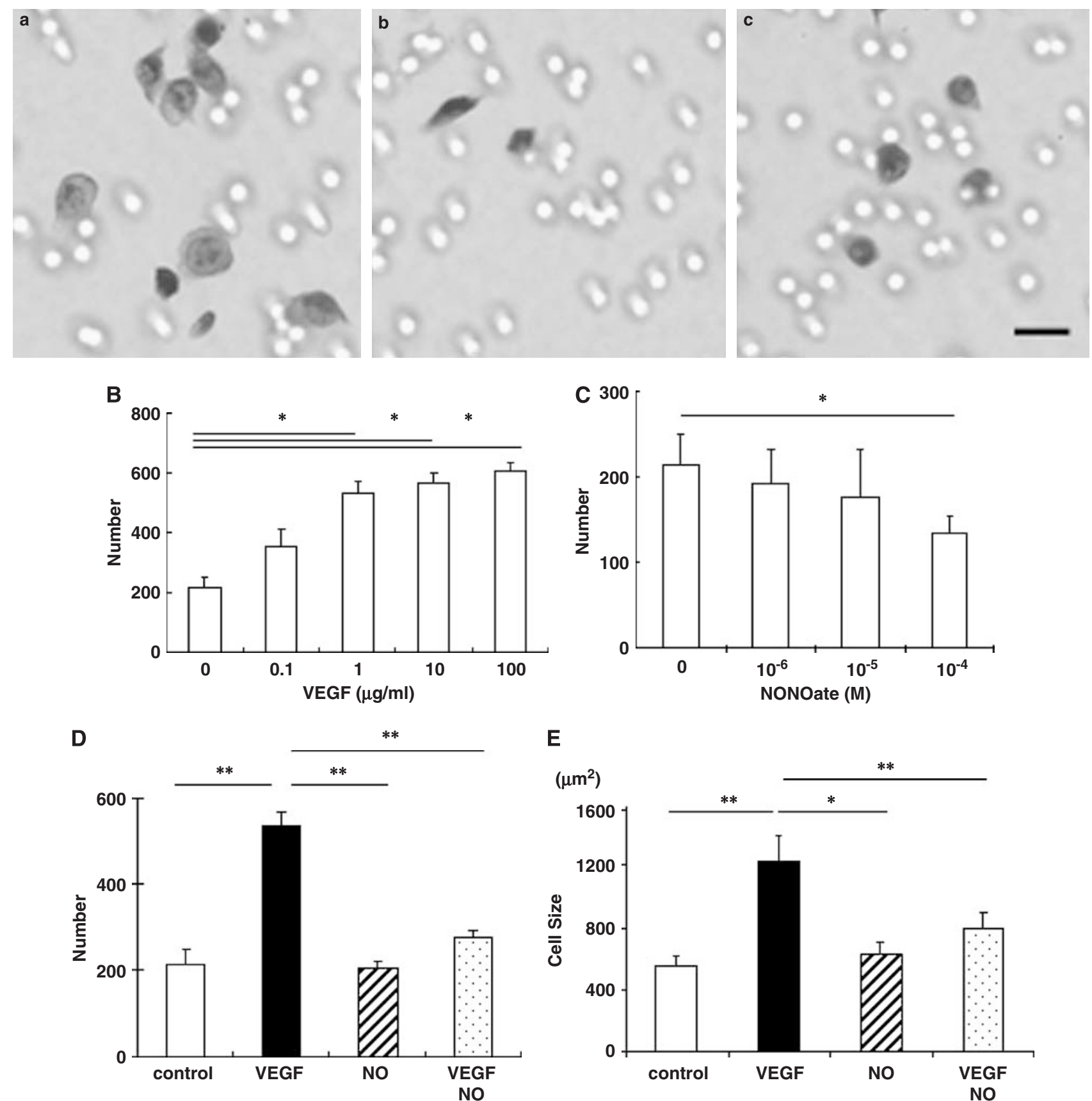

Figure 6 Macrophage migration with stimulation of VEGF and/or NONOate. (A) Hematoxylin staining for migrating cells in Boyden chamber assay at $2 \mathrm{~h}$.

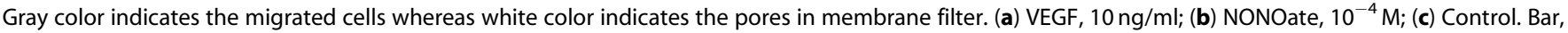
$10 \mu \mathrm{m}$. (B) The number of migrated cells in response to various concentrations of VEGF at $2 \mathrm{~h}$. (C) The number of migrated cells in response to various concentrations of NONOate at $2 \mathrm{~h}$. (D) The number of migrated cells at $2 \mathrm{~h}$ after stimulation of $10 \mathrm{ng} / \mathrm{ml}$ VEGF and/or NONOate (NO). (E) Cell size of macrophage under stimulation of VEGF and/or NONOate. ${ }^{*} P<0.05,{ }^{*} P<0.001$.

stimuli, such as interferon- $\gamma$ or tumor necrosis factor- $\alpha$, whereas exposure to IL-4 and IL-13 results in an alternative activation of macrophage in renal inflammation. ${ }^{31}$ Chow et al $^{11}$ have shown that CD68 macrophages are composed of two phenotypes regarding CD169 and iNOS expressions.
Hence, macrophages could have diverse effects that can be accounted for by their phenotype.

Endothelium-derived NO may have an important role in negatively regulating macrophage migration. Some studies have reported that an administration of L-arginine, which is a 
a

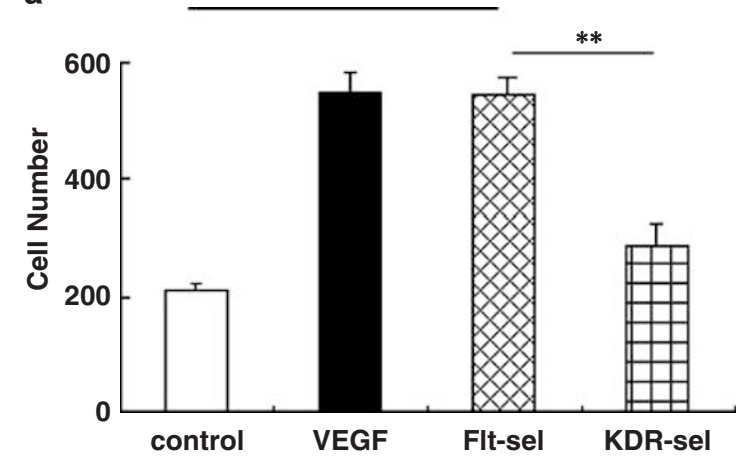

C

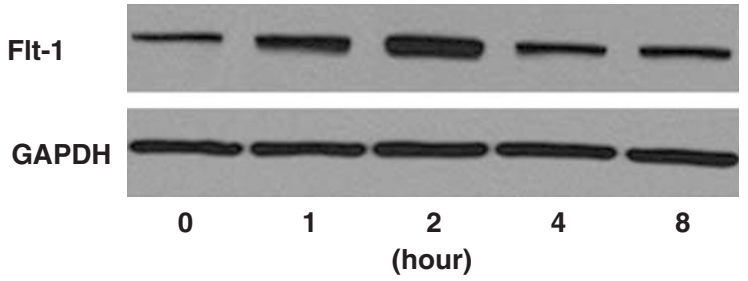

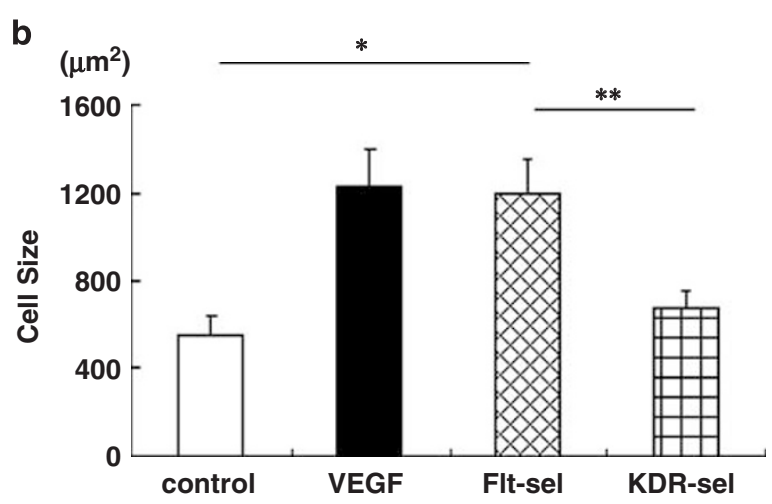

d FIt-1

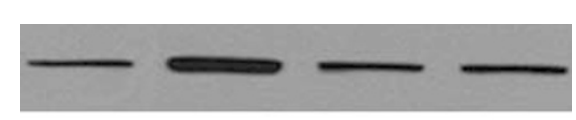

GAPDH

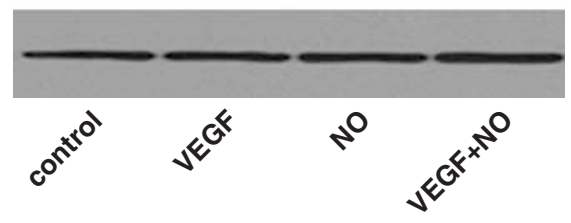

f

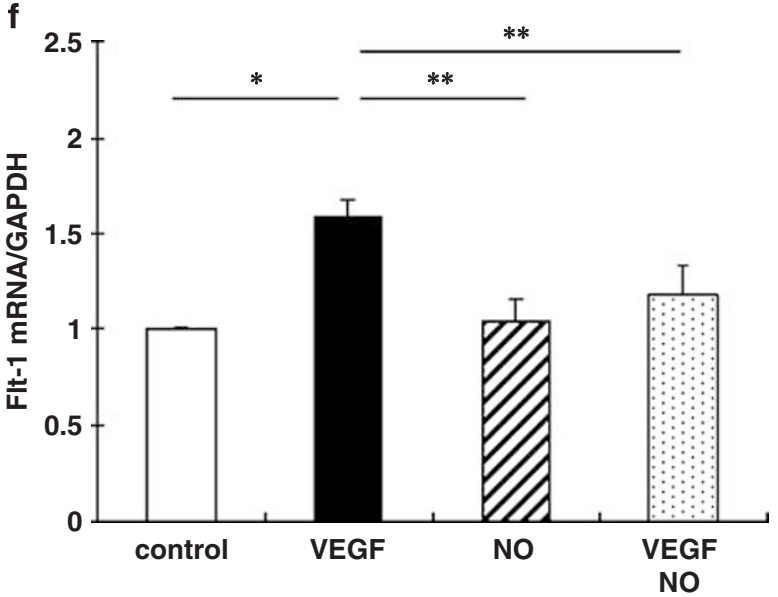

Figure 7 Macrophage migration and cell spreading in response to VEGF mutants, which selectively bind either Flt-1 or KDR. (a) Number of migrated cells $2 \mathrm{~h}$ after stimulation of Flt1-sel or KDR-sel VEGF mutant in Boyden chamber migration assay. (b) Size of macrophage $2 \mathrm{~h}$ after stimulation of Flt1-sel or KDRsel. (c) Western blotting for the time course of Flt-1 protein synthesis in response to VEGF. (d) Representative Flt-1 protein synthesis $2 \mathrm{~h}$ after stimulation with VEGF and/or NONOate (NO). (e) Quantitative analysis for Flt-1 protein synthesis in response to $10 \mathrm{ng} / \mathrm{ml} \mathrm{VEGF} \mathrm{with/without} 10^{-4} \mathrm{M}$ NONOate (NO). The intensity of Flt-1 was corrected by GAPDH protein. (f) Flt-1 mRNA expression at $30 \mathrm{~min}$ in response $10 \mathrm{ng} / \mathrm{ml}$ VEGF and/or $10^{-4} \mathrm{M}$ NONOate (NO). The relative expression of Flt-1 mRNA was corrected by GAPDH mRNA. ${ }^{\star} P<0.01,{ }^{* *} P<0.05$.

substrate for NOS to produce NO, attenuates macrophage infiltration in renal disease. ${ }^{32}$ On the other hand, NO inhibition by genetic or pharmaceutical maneuvers can accelerate renal injury and stimulate immune cell infiltration, including the induction of adhesion molecules on endothelial cell, ${ }^{33-35}$ suggesting an anti-inflammatory role of NO. In this study, we showed that Flt-1 expression on macrophage was positively regulated by VEGF, but negatively by NO. Similarly, we have recently shown that VEGF upregulates the expression of VEGFRs in absence of NO in the endothelial cell. ${ }^{20}$ Thus, negative regulation of VEGFRs by NO could be a key mechanism to maintain vascular integrity and macrophage migration under VEGF stimulation. ${ }^{18}$ Our findings that NO negatively regulated the cell spreading response in macrophages in response to VEGF are also compatible with previous studies that have shown that NO could inhibit actin polymerization in response to VEGF on neutrophils. ${ }^{36}$

In summary, VEGF activates macrophage migration by Flt-1. NO can modulate the macrophage response to VEGF. Thus, we propose that conditions associated with marked endothelial dysfunction and low NO levels could favor 

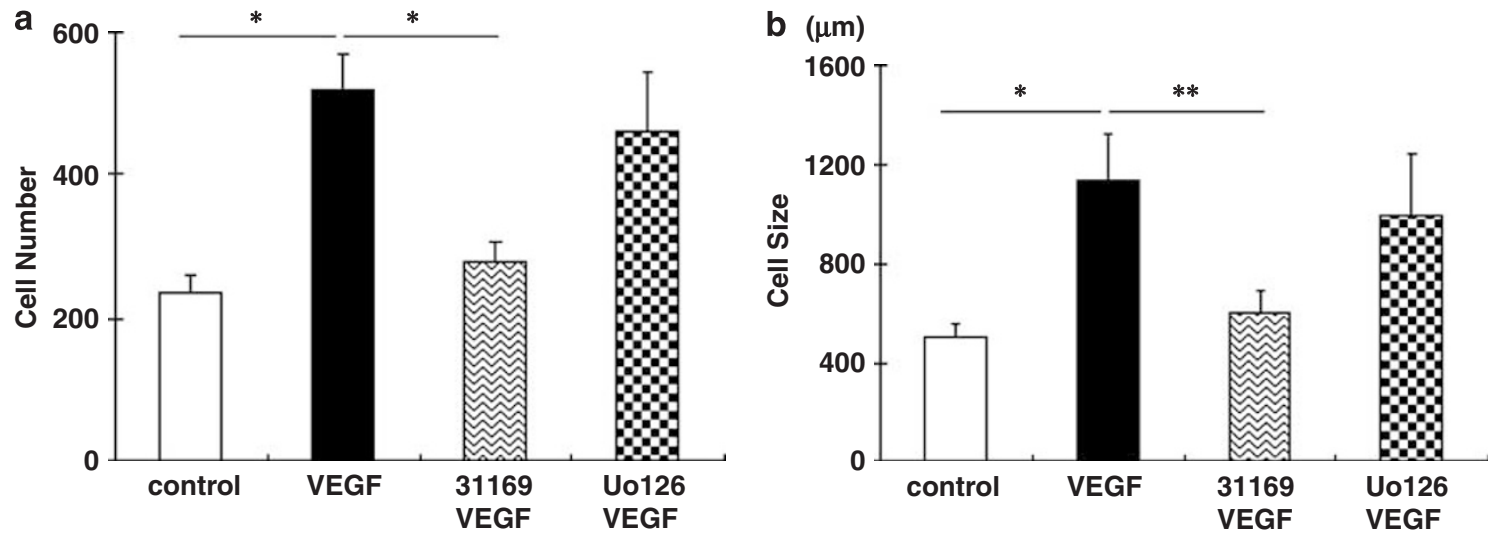

Figure 8 Macrophage migration in response to VEGF was mediated significantly by $\mathrm{p} 38$ but not by ERK. (a) The number of migrated cells at $2 \mathrm{~h}$ after stimulation of VEGF with either 31169 (a specific inhibitor of p38 MAP kinase) or Uo126 (a specific inhibitor of ERK). (b) Cell size of macrophage under stimulation of VEGF with either 31169 or Uo126. ${ }^{\star} P<0.01,{ }^{* *} P<0.05$.

proinflammatory effects of VEGF that would result in enhanced macrophage activation. This might partially explain how VEGF causes vascular disease in conditions such as diabetes.

\section{ACKNOWLEDGEMENTS}

This study was supported by support from NIH DK 52121 and by generous funds from Gatorade. We thank Dr Richard J Johnson (University of Florida, Gainesville, FL) for precious guidance of these experiments.

1. Galkina E, Ley K. Leukocyte recruitment and vascular injury in diabetic nephropathy. J Am Soc Nephrol 2006;17:368-377.

2. Tesch GH. MCP-1/CCL2: a new diagnostic marker and therapeutic target for progressive renal injury in diabetic nephropathy. Am J Physiol Renal Physiol 2008;294:F697-F701.

3. Chow F, Ozols E, Nikolic-Paterson DJ, et al. Macrophages in mouse type 2 diabetic nephropathy: correlation with diabetic state and progressive renal injury. Kidney Int 2004;65:116-128.

4. Furuta $T$, Saito $T$, Ootaka $T$, et al. The role of macrophages in diabetic glomerulosclerosis. Am J Kidney Dis 1993;21:480-485.

5. Sassy-Prigent C, Heudes D, Mandet $C$, et al. Early glomerular macrophage recruitment in streptozotocin-induced diabetic rats. Diabetes 2000;49:466-475.

6. Ikezumi $\mathrm{Y}$, Hurst LA, Masaki $\mathrm{T}$, et al. Adoptive transfer studies demonstrate that macrophages can induce proteinuria and mesangial cell proliferation. Kidney Int 2003;63:83-95.

7. Yoshida $H$, Yashiro $M$, Liang $P$, et al. Mesangiolytic glomerulopathy in severe congestive heart failure. Kidney Int 1998;53:880-891.

8. Basta $G$, Lazzerini $G$, Massaro $M$, et al. Advanced glycation end products activate endothelium through signal-transduction receptor RAGE: a mechanism for amplification of inflammatory responses. Circulation 2002;105:816-822.

9. Sugimoto $\mathrm{H}$, Shikata $\mathrm{K}$, Hirata $\mathrm{K}$, et al. Increased expression of intercellular adhesion molecule-1 (ICAM-1) in diabetic rat glomeruli: glomerular hyperfiltration is a potential mechanism of ICAM-1 upregulation. Diabetes 1997:46:2075-2081.

10. Okada S, Shikata K, Matsuda M, et al. Intercellular adhesion molecule1-deficient mice are resistant against renal injury after induction of diabetes. Diabetes 2003;52:2586-2593.

11. Chow FY, Nikolic-Paterson DJ, Ozols E, et al. Monocyte chemoattractant protein-1 promotes the development of diabetic renal injury in streptozotocin-treated mice. Kidney Int 2006; 69:73-80.

12. de Vriese AS, Tilton RG, Elger $M$, et al. Antibodies against vascular endothelial growth factor improve early renal dysfunction in experimental diabetes. J Am Soc Nephrol 2001;12:993-1000.
13. Flyvbjerg A, Dagnaes-Hansen F, De Vriese AS, et al. Amelioration of long-term renal changes in obese type 2 diabetic mice by a neutralizing vascular endothelial growth factor antibody. Diabetes 2002;51:3090-3094.

14. Kang $\mathrm{DH}$, Joly $\mathrm{AH}$, Oh SW, et al. Impaired angiogenesis in the remnant kidney model: I. Potential role of vascular endothelial growth factor and thrombospondin-1. J Am Soc Nephrol 2001;12: 1434-1447.

15. Ostendorf $\mathrm{T}$, Kunter $\mathrm{U}$, Eitner $\mathrm{F}$, et al. $\operatorname{VEGF(165)~mediates~glomerular~}$ endothelial repair. J Clin Invest 1999;104:913-923.

16. Celletti FL, Waugh JM, Amabile PG, et al. Vascular endothelial growth factor enhances atherosclerotic plaque progression. Nat Med 2001:7:425-429.

17. Nakagawa T, Sato W, Glushakova O, et al. Diabetic eNOS knockout mice develop advanced diabetic nephropathy. J Am Soc Nephrol 2007;18:539-550.

18. Nakagawa T. Uncoupling of the VEGF-endothelial nitric oxide axis in diabetic nephropathy: an explanation for the paradoxical effects of VEGF in renal disease. Am J Physiol Renal Physiol 2007; 292:F1665-F1672.

19. Nakagawa T, Lan HY, Zhu HJ, et al. Differential regulation of VEGF by TGF-beta and hypoxia in rat proximal tubular cells. Am J Physiol Renal Physiol 2004;287:F658-F664.

20. Nakagawa $T$, Sato $W$, Sautin $Y Y$, et al. Uncoupling of vascular endothelial growth factor with nitric oxide as a mechanism for diabetic vasculopathy. J Am Soc Nephrol 2006;17:736-745.

21. Ichinose K, Maeshima Y, Yamamoto Y, et al. Antiangiogenic endostatin peptide ameliorates renal alterations in the early stage of a type 1 diabetic nephropathy model. Diabetes 2005;54: 2891-2903.

22. Stout LC, Kumar S, Whorton EB. Focal mesangiolysis and the pathogenesis of the Kimmelstiel-Wilson nodule. Hum Pathol 1993;24:77-89.

23. Stout LC, Kumar S, Whorton EB. Insudative lesions-their pathogenesis and association with glomerular obsolescence in diabetes: a dynamic hypothesis based on single views of advancing human diabetic nephropathy. Hum Pathol 1994;25: 1213-1227.

24. Keyt BA, Nguyen HV, Berleau LT, et al. Identification of vascular endothelial growth factor determinants for binding KDR and FLT-1 receptors. Generation of receptor-selective VEGF variants by site-directed mutagenesis. J Biol Chem 1996;271: 5638-5646.

25. Breyer MD, Bottinger E, Brosius III FC, et al. Mouse models of diabetic nephropathy. J Am Soc Nephrol 2005;16:27-45.

26. Kanetsuna $Y$, Takahashi $K$, Nagata $M$, et al. Deficiency of endothelial nitric-oxide synthase confers susceptibility to diabetic nephropathy in nephropathy-resistant inbred mice. Am J Pathol 2007;170: 1473-1484. 
27. Sugimoto $\mathrm{H}$, Hamano $\mathrm{Y}$, Charytan $\mathrm{D}$, et al. Neutralization of circulating vascular endothelial growth factor (VEGF) by anti-VEGF antibodies and soluble VEGF receptor 1 (sFlt-1) induces proteinuria. J Biol Chem 2003;278:12605-12608.

28. Barleon B, Sozzani S, Zhou D, et al. Migration of human monocytes in response to vascular endothelial growth factor (VEGF) is mediated via the VEGF receptor flt-1. Blood 1996;87:3336-3343.

29. Kanno $S$, Oda N, Abe M, et al. Roles of two VEGF receptors, Flt-1 and $\mathrm{KDR}$, in the signal transduction of VEGF effects in human vascular endothelial cells. Oncogene 2000;19:2138-2146.

30. Rousseau S, Houle F, Landry J, et al. p38 MAP kinase activation by vascular endothelial growth factor mediates actin reorganization and cell migration in human endothelial cells. Oncogene 1997;15: 2169-2177.

31. Wang $Y$, Wang $Y P$, Zheng $G$, et al. Ex vivo programmed macrophages ameliorate experimental chronic inflammatory renal disease. Kidney Int 2007;72:290-299.
32. Vos $\mathrm{IH}$, Rabelink TJ, Dorland $\mathrm{B}$, et al. -arginine supplementation improves function and reduces inflammation in renal allografts. J Am Soc Nephrol 2001;12:361-367.

33. Heeringa $\mathrm{P}$, van Goor $\mathrm{H}$, Itoh-Lindstrom $\mathrm{Y}$, et al. Lack of endothelial nitric oxide synthase aggravates murine accelerated anti-glomerular basement membrane glomerulonephritis. Am J Pathol 2000;156: 879-888.

34. Lefer DJ, Jones SP, Girod WG, et al. Leukocyte-endothelial cell interactions in nitric oxide synthase-deficient mice. Am J Physiol 1999;276:H1943-H1950.

35. Sakamoto T, Ishibashi T, Sakamoto N, et al. Endogenous NO blockade enhances tissue factor expression via increased $\mathrm{Ca} 2+$ influx through MCP-1 in endothelial cells by monocyte adhesion. Arterioscler Thromb Vasc Biol 2005;25:2005-2011.

36. Forslund T, Nilsson HM, Sundqvist T. Nitric oxide regulates the aggregation of stimulated human neutrophils. Biochem Biophys Res Commun 2000;274:482-487. 